\title{
EPIDEMIOLOGICAL STUDY OF OSTEOARTICULAR INFECTIONS IN CHILDREN
}

\section{ESTUDO EPIDEMIOLÓGICO DAS INFECÇÕES OSTEOARTICULARES EM CRIANÇAS}

\author{
Frederico Carlos Jaña Neto ${ }^{1}$, Caroline Sartori Ortega ${ }^{2}$, Ellen de Oliveira Goiano ${ }^{3}$ \\ 1. Universidade Nove de Julho (UNINOVE), São Paulo, SP, Brazil. \\ 2. Faculdade de Medicina da Universidade Nove de Julho (UNINOVE), São Paulo, SP, Brazil. \\ 3. Orthopedics and Traumatology Group at the Mandaqui Hospital Complex, São Paulo, SP, Brazil.
}

\begin{abstract}
Objective: To analyze the characteristics of patients diagnosed with pediatric osteoarticular infections treated in a level III trauma center in São Paulo, Brazil. Methods: We retrospectively analyzed patients admitted between September 2012 and August 2014. The outcomes analyzed were: age, sex, diagnosis, etiologic agent, anatomic location, time to diagnosis, history of previous trauma and infection, laboratory tests, treatment, and complications. Results: Twenty patients were included, 50\% with septic arthritis, 35\% with osteomyelitis, and $15 \%$ with both. Boys were predominant (80\%), and the mean age was 6.6 years. The most common etiologic agent was Staphylococcus aureus. C-reactive protein value and erythrocyte sedimentation rate were elevated. The infections were treated with antibiotic therapy (intravenous and oral) and oxacillin was most frequently used. Most patients underwent at least one surgical procedure, and $35 \%$ of patients had complications. Conclusion: This epidemiological mapping identified clinical and demographic characteristics which are useful for improving preparation for care. Future prospective studies with longer patient follow-up and the development of treatment protocols are needed to improve therapeutic decision-making and the prognosis of children with suspected osteoarticular infections. Evidence Level II; Prognostic studies - Investigation of the effect of patient characteristics on the outcome of the disease.
\end{abstract}

Keywords: Arthritis, infectious. Osteomyelitis. Pediatrics/ epidemiology.

\section{RESUMO}

Objetivo: analisar as características dos pacientes com diagnóstico de infecção osteoarticular pediátrica, tratados em um hospital de nível terciário em São Paulo. Métodos: Analisamos, retrospectivamente, os pacientes internados no período entre setembro de 2012 e agosto de 2014. As variáveis analisadas foram: idade, gênero, diagnóstico, agente etiológico, localização anatômica, tempo de diagnóstico, histórico de infecção e trauma prévio, exames laboratoriais, tratamento e complicações. Resultados: 20 pacientes foram incluídos, 50\% com artrite séptica, 35\% osteomielite e $15 \%$ ambos. Houve predomínio do gênero masculino (80\%), média de idade de 6,6 anos. O agente etiológico mais comum foi o Staphiloccocus aureus. Ambos os exames laboratoriais PCR e VHS aumentaram. O tratamento foi a antibioticoterapia (via endovenosa e oral) e a oxacilina foi o medicamento mais utilizado. A maioria dos pacientes foram submetidos ao menos a um procedimento cirúrgico e $35 \%$ dos pacientes apresentaram complicações. Conclusão: Este mapeamento epidemiológico identificou características clínicas e demográficas úteis para melhorar o preparo da equipe para o atendimento. Pesquisas futuras de caráter prospectivo, com maior tempo de acompanhamento dos pacientes e a elaboração de protocolos de atendimento são necessárias para melhorar a tomada de decisão terapêutica e o prognóstico de crianças com suspeita de infecção osteoarticular. Nível de Evidência Il; Estudos prognósticos - Investigação do efeito de característica de um paciente sobre o desfecho da doença.

Descritores: Artrite Infecciosa. Osteomielite. Pediatria/epidemiologia.

Citation: Jaña Neto FC, Ortega CS, Goiano EO. Epidemiological study of osteoarticular infections in children. Acta Ortop Bras. [online]. 2018;26(3):201-5. Available from URL: http://www.scielo.br/aob.

\section{INTRODUCTION}

Osteoarticular infections in children, such as osteomyelitis and septic arthritis, are a growing problem with potential for systemic aftereffects, since they can progress to irreversible joint damage and motor injury or sepsis. Diagnosis of joint or bone infection in children is frequently difficult, since this disease may initially be asymptomatic., ${ }^{1,2}$ Early pharmaceutical and surgical treatment are necessary to reduce permanent damage. Evaluation and treatment of these patients require communication and coordination between various hospital departments including the emergency unit, pediatrics, orthopedics, infectious diseases, laboratory services, radiology, nursing, and social services. ${ }^{3-5}$

Clinical manifestations of osteoarticular infections in children vary according to age and the microorganism and bone structure involved.

All authors declare no potential conflict of interest related to this article.

Work conducted at the Mandaqui Hospital Complex, São Paulo, SP, Brazil.

Correspondence: Frederico Carlos Jaña Neto. Av. Angélica, 2491 - $9^{\circ}$ andar, Bela Vista, São Paulo, SP, Brazil. 01227-200. fredericojana@uni9.pro.br 
According to Blyth et al., ${ }^{6}$ the incidence of acute and sub-acute hematogenic osteomyelitis is 2.9 per 100,000 in children under 13 years of age, and principally affects the distal metaphysis of the femur and the proximal metaphysis of the tibia. Septic arthritis is the predominant infection in infants and children, with nearly half of cases occurring before 20 years of age. Its incidence varies from 5.5 to 12 cases per 100,000 children, and boys are three times more affected than girls. The knees, hips, elbows, and shoulders are most affected, but nearly $20 \%$ of patients are affected in more than one joint. The main symptoms include localized pain, fever, irritability, and functional limitation. ${ }^{4,5}$ The clinical characteristics, X-ray findings, and laboratory results should be considered in conjunction for the diagnosis. In general, bone cultures, subperiosteal exudate, and joint fluid provide the microbiological diagnosis in $30 \%$ to $80 \%$ of cases. ${ }^{1}$ In Brazil, few epidemiological studies have been published on bone and joint infections in children. These studies provide important information that helps identify clinical and demographic differences between patients which is useful in standardizing assistance procedures and establishing guidelines for starting or continuing organized care in a pediatric hospital. Therefore, the objective of this study was to retrospectively analyze the characteristics of patients with a diagnosis of pediatric osteoarticular infection who were treated at a tertiary hospital in São Paulo, Brazil, from September 2012 to August 2014.

\section{MATERIALS AND METHODS}

This transversal retrospective study was conducted at the Mandaqui Hospital Complex in São Paulo, and was approved by the institutional review board (process 902.454). Patients aged 0 to 17 years who were admitted between September 2012 and August 2014 with a clinical and laboratory diagnosis of osteoarticular infection were included. Patients whose charts were incomplete were excluded from the study.

Data for each patient were collected using the HospGestor program (https://www.hgresidencia.com.br/ortopmandaqui), which stores the charts for patients who are hospitalized in this service. The charts are completed daily and in a standardized manner by the orthopedic physicians in the service. Patients who were able to read and write or their parents/guardians were contacted and signed an informed consent term before data were obtained from the database and used.

- The variables analyzed were:

- Demographic characteristics: age ( $<1$ year, 1-5 years, 6-10 years, $>10$ years) and sex

- Type of infection (criteria for diagnosis): ${ }^{7}$

- Septic arthritis: acute joint infection, blood culture, and signs of acute arthritis and joint effusion.

- Osteomyelitis: chronic bone infection, blood culture, and X-ray imaging

Osteomyelitis + septic arthritis: concomitant bone and joint infec-

tions, blood culture, joint effusion, and X-ray imaging.

- Anatomical location of the infection

- Time to diagnosis (in days)

- Identification of etiologic agents (culture)

- History of previous infection, comorbidities, or trauma

- Laboratory exams:

- C-reactive protein (CRP, normal value $<1 \mathrm{mg} / \mathrm{dl})^{8}$

- Erythrocyte sedimentation rate (ESR, normal value $<20 \mathrm{~mm} / \mathrm{h})^{8}$

- Treatment (pharmaceutical and surgical)

- Complications

The statistical analysis was calculated using the mean and standard deviation of the quantitative variables (95\% confidence interval), as well as frequency analysis (percentage) for the categorical variables (95\% confidence interval).

\section{RESULTS}

The initial sample was composed of 22 patients who fit the selection criteria. Of these, two were excluded because of missing data in their charts. Of the 20 patients included, half had a diagnosis of septic arthritis (50\%), followed by osteomyelitis (35\%) and associated osteomyelitis and septic arthritis (15\%). (Figure 1)

Boys were more predominantly affected (80\%) and the mean age was 6.6 years (DP $\pm 5.4 ; 0-17$ ); the boys tended to be older than the girls ( $8.8 \pm 4.7$ years versus $4.3 \pm 4.5$ years, respectively). Patients older than 10 years were more severely affected (35\%). (Figure 2) As for anatomical location of the infection, three patients presented septic arthritis in the hip, two in the elbow, and five in the knee. The cases of osteomyelitis occurred in the following locations: one in the femur shaft, one at the distal end of the femur, one at the distal end of the tibia, one in the ankle, one in a phalange, another in the clavicle, and one in the humerus. Finally, three patients were diagnosed with septic arthritis associated with osteomyelitis: two cases in the hip and one case of septic arthritis of the elbow and ankle associated with osteomyelitis of the ulna and fibula. The right side was most affected (60\%).

Twelve patients (60\%) reported a history of infection or previous trauma; pulmonary diseases were most frequent (40\%), including bronchiolitis, bronchial pneumonia, pneumonia, and tuberculosis, followed by fractures (5\%), epiphysiolysis of the femoral head (5\%), snakebite injury (5\%), and bacterial conjunctivitis (5\%).

As for the etiologic agents, blood culture detected the growth of isolated pathogens in 11 patients: six cases of Staphylococcus spp. (5 aureus, 1 haemolyticus), one of Acinetobacter baumannii, one of Streptococcus pyogenes, one of Enterobacter cloacae, and one of Serratia marcelis, and one patient with associated pathogens

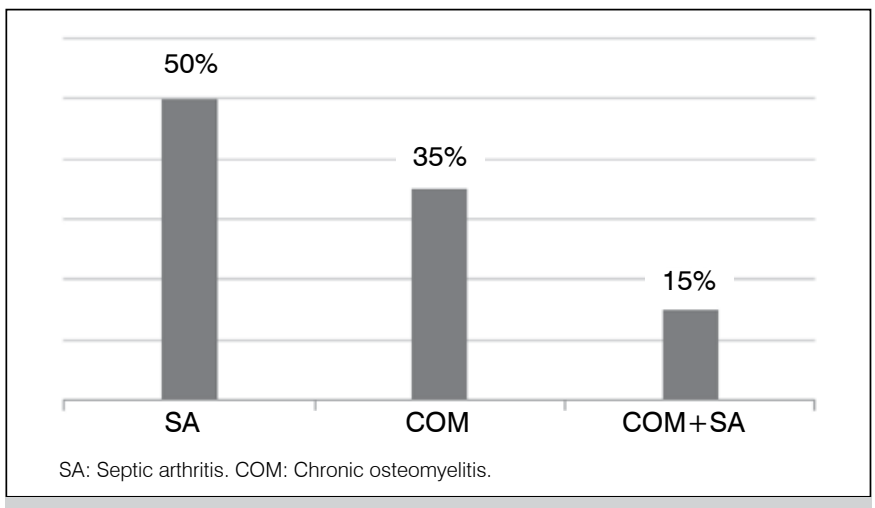

Figure 1. Sample distribution by diagnosis.

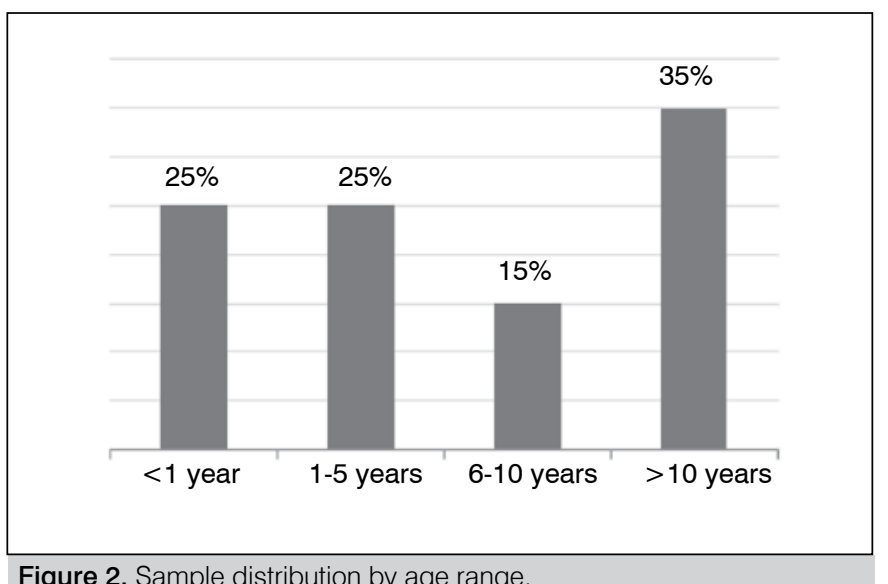

Figure 2. Sample distribution by age range. 
(Pseudomonas aeruginosa and Acinetobacter baumannii). In the other patients no growth of biological agents was found.

CRP level and ESR were assessed in all patients at the time of hospital admission. Among the patients with septic arthritis, the mean serum concentration of CRP was $15 \mathrm{mg} / \mathrm{dl}$; for patients with osteomyelitis, this value was $10.55 \mathrm{mg} / \mathrm{dl}$, and in cases of osteomyelitis associated with septic arthritis, the average value was 22.9mg/dl. (Figure 3) The average ESR was $63 \mathrm{~mm} / \mathrm{h}, 45.1$ $\mathrm{mm} / \mathrm{h}$ and $70.7 \mathrm{~mm} / \mathrm{h}$, respectively. (Figure 4)

The mean hospital stay was 26.9 days (4-106). The treatment involved intravenous antibiotic therapy during hospitalization and oral antibiotics after discharge in all patients. Mean therapy duration (intravenous and oral) was 3.7 weeks. Oxacillin was the most frequent antibiotic, and was used in $70 \%$ of the patients, followed by amikacin (15\%) and vancomycin (10\%). Of the 20 patients included, 16 (80\%) underwent at least one surgical procedure, which was most frequently surgical cleaning. In six patients the infection recurred, and additional surgery was performed when necessary. One patient presented joint stiffness due to immobilization. Table 1 shows the clinical characteristics and treatment of each patient included in the study.

\section{DISCUSSION}

This study analyzed the clinical and epidemiological characteristics and treatment of osteoarticular infections in children, based on data collected from patients treated at a tertiary hospital. The results showed predominantly male patients with a mean age of 6.6 years.

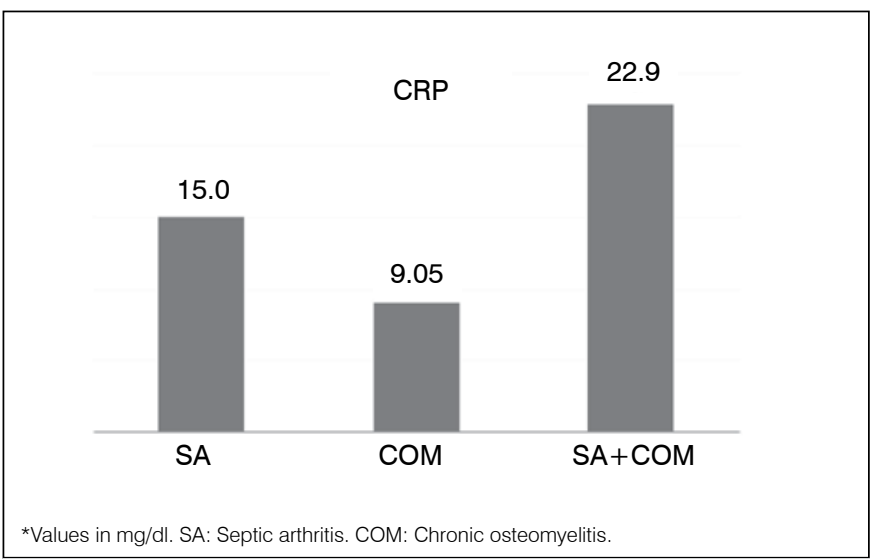

Figure 3. Sample distribution by diagnosis and C-reactive protein level (CRP).

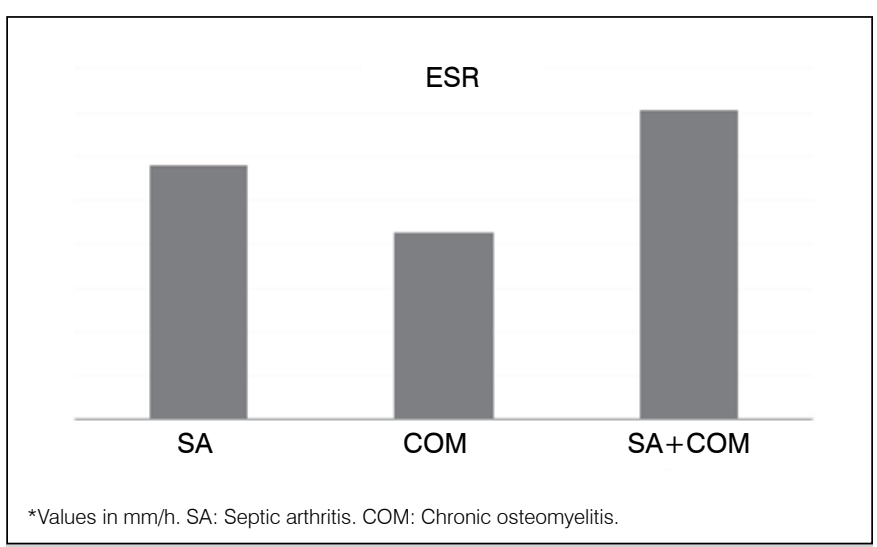

Figure 4. Sample distribution by diagnosis and erythrocyte sedimentation rate (ESR).
Half of the patients were diagnosed with septic arthritis (50\%), followed by osteomyelitis (35\%), and septic arthritis associated with osteomyelitis (15\%), and the majority of the cases affected the hip and knee joints. Grammatico-Guillon et al. ${ }^{9}$ analyzed 2911 patients with osteoarticular infections using the French National Hospital Database, and reported similar data in relation to the greater prevalence in boys than in girls (24 versus 19 per 100,000 inhabitants, respectively), with $52 \%$ of the cases of septic arthritis and $44 \%$ of osteomyelitis. In a prospective epidemiological study, Mitha et al. ${ }^{10}$ found $52 \%$ of cases involved septic arthritis and $41 \%$ osteomyelitis, with $80 \%$ of cases involving the legs.

Most of the studies show that confirmation of the diagnosis of septic arthritis, osteomyelitis, or both should be based on signs and symptoms found in imaging examinations and laboratory tests. ${ }^{10-13}$ However, bone alterations only become apparent in X-rays after seven to 10 days of infection, and initial laboratory data can present within normal limits. ${ }^{8}$ Furthermore, approximately $30 \%$ to $50 \%$ of causative pathogens are not identified through culturing, since some microorganisms require specific culture media or a longer growth period. ${ }^{12}$ In the present study, $40 \%$ of the cases demonstrated negative culture results.

Chen et al. ${ }^{8}$ examined 27 children, $55.6 \%$ of whom had a diagnosis of concomitant septic arthritis and osteomyelitis. These authors believed that the use of more precise instruments, such as magnetic resonance imaging, computed tomography, and bone scintigraphy, may have led to a better definition of the pathologies in the bones and joints, thus improving the accuracy of the diagnosis. These authors also observed high CRP and ESR levels in all patients.

According to Dodwell et al., ${ }^{12}$ approximately $85 \%$ of children with osteomyelitis and $100 \%$ of children with osteomyelitis associated with septic arthritis presented elevated CRP and ESR levels. Pääkkönen et al. ${ }^{7}$ analyzed 265 children with positive culture results and observed that, due to the rapid normalization of serum CRP results in the first week, this examination is slightly more sensitive for diagnosis than ESR, but the best sensitivity for diagnosis (98\%) was obtained from a combination of the results of both tests. In the present study, $100 \%$ of patients with septic arthritis, $57 \%$ of patients with osteomyelitis, and $100 \%$ with concomitant osteomyelitis and septic arthritis had elevated CRP values. ESR values were higher in $90 \%$ of cases of septic arthritis, $57 \%$ of cases of osteomyelitis, and $100 \%$ of cases with concomitant septic arthritis and osteomyelitis. According to Ceroni et al., ${ }^{11}$ direct inoculation of the microorganism into the bone or joint after trauma, internal fracture fixation, or soft tissue infections occurs less frequently in children. Most pediatric bone and joint infections are hematogenous in origin, and the respiratory tract is considered the main route of entry for the pathogen. Bacteria such as Streptococcus pneumoniae and Staphylococcus aureus may reside in the surface of the respiratory mucosa and are able to penetrate into the bloodstream, spread, and invade distant organs.

In this study, $40 \%$ of the patients reported a history of pulmonary diseases, and $25 \%$ of these were contaminated by Staphylococcus aureus. This finding is similar to other studies. Gafur et al. ${ }^{14}$ studied 554 children in an American medical center in Dallas and reported that Staphylococcus aureus was the main causative agent of musculoskeletal infections. Chen et al. ${ }^{8}$ found Staphylococcus aureus in $83.3 \%$ of cases, and a study by Grammatico-Guillon et al. ${ }^{9}$ found it in $63 \%$ of the cases. According to Dodwell et al., ${ }^{12}$ although Staphylococcus aureus is typically described as the most common cause of pediatric infections, gram-negative bacteria may affect approximately $60 \%$ of children below 4 years of age, and Kingella kingae has been the cause of approximately $82 \%$ of the infections in this age range. However, detection of this microorganism is 
Table 1. Patient characteristics.

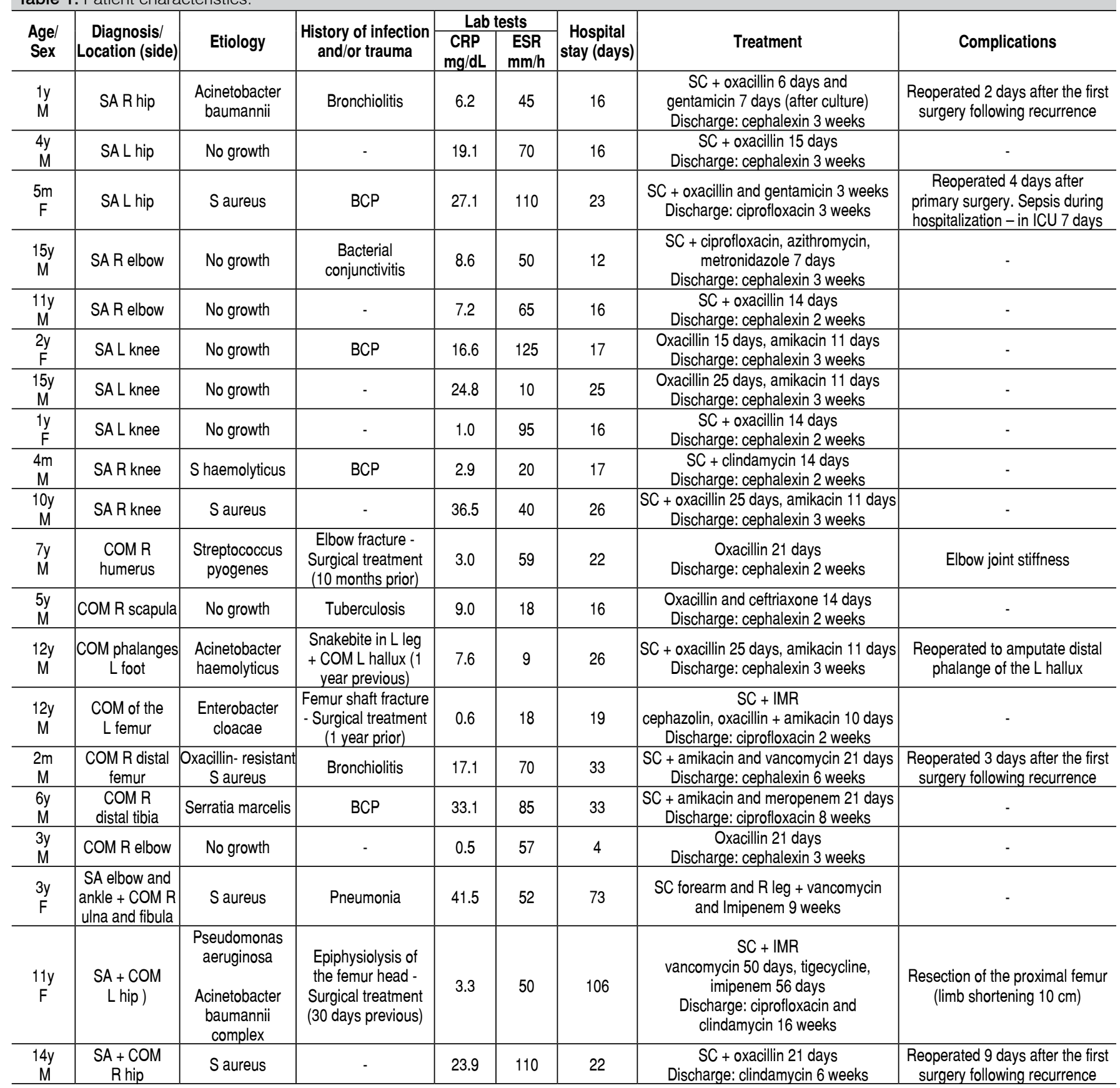

y: years; m: months; M: male; F: female; SA: Septic arthritis. COM: Chronic osteomyelitis; R: right; L: left; S Aureus: Staphylococcus Aureus, BCP: Bronchial pneumonia; CRP: C-reactive protein; ESR: erythrocyte sedimentation rate; SC: Surgical cleaning; w: weeks; IMR: implant material removed.

complex, and there is no way to specify its exact frequency due to the difficulty of isolating it in routine exams.

Kocher et al. ${ }^{15}$ developed guidelines to treat pediatric orthopedic infections and emphasized the inclusion of antibiotic therapy and surgery according to need. The patients are usually admitted to the hospital, and until exams to identify the pathogen are completed, treatment is begun with empirical antibiotics. Empirical treatment is used to address the most likely pathogens, and the medication is chosen according to the age of the child, the local prevalence of infectious agents, and early laboratory results. When the results of culture are available, antimicrobial therapy may be modified depending on the microorganism and the pattern of susceptibility. ${ }^{11,12}$ According to Kaplan et al., ${ }^{16}$ oxacillin is recommended as the first option along with vancomycin in cases of critically ill children. Clindamycin is an option for less serious cases in which there is no suspicion of bacteremia. These data corroborate the findings of the present study.

The duration and administration route for antibiotic therapy depend on the virulence of the pathogen, the location of the infection, and the clinical and laboratory response to treatment. ${ }^{11,12}$ According to Kaplan et al., ${ }^{16}$ transitioning from intravenous to oral administration is important to complete treatment and avoid complications. It is recommended that treatment last a total of at least three weeks, depending on the patient's clinical response. In the sample analyzed in this study, all patients received intravenous antibiotic therapy during hospitalization and oral antibiotics after discharge, with an average total duration 
of six weeks. The average hospital stay was 26 days, while in the study by Grammatico-Guillon et al. ${ }^{7}$ it was 8.6 days. However, our sample included two serious cases of septic arthritis and concomitant osteomyelitis, which required several surgical procedures.

For Kaplan et al., ${ }^{16}$ multiple surgical procedures are often needed in the most serious cases of osteoarticular infection. In the study by Chen et al., ${ }^{8} 74.1 \%$ of the patients needed surgical intervention. In this present study, $80 \%$ of patients underwent at least one surgical procedure, most frequently surgical cleaning.

The main limitations of this study include retrospective analysis of the data, small sample size, and lack of long-term patient follow-up. The importance of prospective studies with longer patient follow-up is evident, as well as complete care protocols for children with suspected osteoarticular infection which include physical examination, laboratory exams and imaging, empirical antibiotic therapy, and definitive surgical treatment. Standardization of procedures for care and treatment may improve therapeutic decision-making and lead to a better prognosis for these patients.

\section{CONCLUSION}

Epidemiological mapping of pediatric patients with osteoarticular infections identified clinical and demographic characteristics which can help the team prepare to attend future cases. Additional prospective studies with longer patient follow-up and the creation of care protocols are necessary to improve therapeutic decision-making and the prognosis for children with suspected osteoarticular infection.

AUTHORS' CONTRIBUTIONS: Each author made significant individual contributions to this manuscript. CSO (0000-0001-9151-8101)*, EOG (00000001-9518-0574)* and FCJN (0000-0001-6374-4398)*: each helped draft the manuscript; CSO and EOG collected the data; FCJN evaluated the data from the statistical analysis; CSO, EOG, and FCJN conducted the bibliographic research, revised the manuscript, and contributed to the intellectual concept of the study. ${ }^{*}$ ORCID (Open Researcher and Contributor ID).

\section{REFERENCES}

1. Mitha A, Boulyana M, Hue V, Pruvost I, Martinot A; European French-speaking expert group, Dubos F. Consensus in diagnostic definitions for bone or joint infections in children by a Delphi method with European French-speaking experts. Acta Paediatr. 2012;101(8):e350-6.

2. Mathews CJ, Coakley G. Septic arthritis: current diagnostic and therapeutic algorithm. Curr Opin Rheumatol. 2008;20(4):457-62.

3. Copley LA, Kinsler MA, Gheen T, Shar A, Sun D, Browne R. The impact of evidence-based clinical practice guidelines applied by a multidisciplinary team for the care of children with osteomyelitis. J Bone Joint Surg Am. 2013;95(8):686-93.

4. Frank G, Mahoney HM, Eppes SC. Musculoskeletal infections in children. Pediatr Clin North Am. 2005;52(4):1083-106.

5. Deshpande SS, Taral N, Modi N, Singrakhia M. Changing epidemiology of neonatal septic arthtitis. J Orthop Surg. 2004;12(1):10-3.

6. Blyth MJ, Kincaid R, Craigen MA, Bennet GC. The changing epidemiology of acute and subacute haematogenous osteomyelitis in children. $J$ Bone Joint Surg Br. 2001;83(1):99-102.

7. Pääkkönen M, Kallio MJ, Kallio PE, Peltola H. Sensitivity of erythrocyte sedimentation rate and C-reactive protein in childhood bone and joint infections. Clin Orthop Relat Res. 2010;468(3):861-6.

8. Chen WL, Chang WN, Chen YS, Hsieh KS, Chen CK, Peng NJ, et al. Acute community-acquired osteoarticular infections in children: high incidence of concomitant bone and joint involvement. J Microbiol Immunol Infect. 2010;43(4):332-8.
9. Grammatico-Guillon L, Maakaroun Vermesse Z, Baron S, Gettner S, Rusch E, Bernard L. Paediatric bone and joint infections are more common in boys and toddlers: a national epidemiology study. Acta Paediatr. 2013;102(3):e120-5.

10. Mitha A, Boutry N, Nectoux E, Petyt C, Lagrée M, Happiette L, et al. Community-acquired bone and joint infections in children: a 1-year prospective epidemiological study. Arch Dis Child. 2015;100(2):126-9.

11. Ceroni D, Kampouroglou G, Valaikaite R, Anderson della Llana R, Salvo D. Osteoarticular infections in young children: what has changed over the last years? Swiss Med Wkly. 2014;144:w13971.

12. Dodwell ER. Osteomyelitis and septic arthritis in children: current concepts. Curr Opin Pediatr. 2013;25(1):58-63.

13. Kotzias Neto A, Oliveira MA, Stipp WN. Avaliação do tratamento da artrite séptica do quadril. Rev Bras Ortop. 2011;46(Suppl 4):14-20.

14. Gafur OA, Copley LA, Hollmig ST, Browne RH, Thornton LA, Crawford SE. The impact of the current epidemiology of pediatric musculoskeletal infection on evaluation and treatment guidelines. J Pediatr Orthop. 2008;28(7):777-85

15. Kocher MS, Mandiga R, Murphy JM, Goldmann D, Harper M, Sundel R, et al. A clinical practice guideline for treatment of septic arthritis in children: efficacy in improving process of care and effect on outcome of septic arthritis of the hip. J Bone Joint Surg Am. 2003;85(6):994-9.

16. Kaplan SL. Recent lessons for the management of bone and joint infections. J Infect. 2014;68 Suppl 1:S51-6. 